\title{
Metal-Free Alkyne Polyhydrothiolation: Synthesis of Functional Poly(vinylenesulfide)s with High Stereoregularity by Regioselective Thioclick Polymerization
}

\author{
By Cathy K. W. Jim, Anjun Qin, Jacky W. Y. Lam, * Faisal Mahtab, Yong Yu, and \\ Ben Zhong Tang*
}

\begin{abstract}
A new synthetic route to sulfur-rich polymers has been developed. The alkyne polyhydrothiolations of 4,4'-thiodibenzenethiol (1) and arylene dipropiolates (2-5) mediated by amines proceed at room temperature in a regioselective fashion, furnishing sole anti-Markovnikov products of poly(vinylenesulfide)s (P1/2-P1/5) with high molecular weights ( $M_{w}$ up to 32300$)$ and high stereoregularities ( $Z$ content up to $81.4 \%$ ) in high yields (up to $98.2 \%$ ). Polymers $\mathrm{P} 1 / 2-\mathrm{P} 1 / 4$ are soluble in common organic solvents. They are optically transparent, allowing almost all visible and IR light to transmit through. Thanks to the high sulfur contents of the polymers, their films show high refractive indices $(n=1.73-1.70)$ in the wavelength region of 500 $1700 \mathrm{~nm}$ as well as high Abbé numbers ( $v_{D}^{\prime}$ up to 539 ) and low optical dispersions ( $D^{\prime}$ down to 0.002 ) at wavelengths important for telecommunications. Their refractivities can be further enhanced ( $n$ up to 2.06) by metal complexation and their films can be crosslinked by UV irradiation, which enables ready fabrication of fluorescent photopatterns.
\end{abstract}

\section{Introduction}

The exploration of effective polymerization reactions for the synthesis of new polymers with novel structures and unique properties is an important area of research in macromolecular science. Addition polymerizations of olefinic monomers have been one of the main routes to synthetic polymers. In the olefinic polymerizations, the monomers are knitted together by carbon-

[*] Prof. B. Z. Tang, Dr. J. W. Y. Lam, C. K. W. Jim, Dr. A. Qin, F. Mahtab, Y. Yu

Department of Chemistry, Institute of Molecular Functional Materials The Hong Kong University of Science \& Technology (HKUST)

Clear Water Bay, Kowloon (Hong Kong, PR China)

E-mail: tangbenz@ust.hk, chjacky@ust.hk

Prof. B. Z. Tang, Dr. J. W. Y. Lam, C. K. W. Jim, Dr. A. Qin, F. Mahtab,

Y. Yu

HKUST Fok Ying Tung Research Institute

Nansha, Guangzhou (PR China)

Prof. B. Z. Tang, Dr. A. Qin

Department of Polymer Science and Engineering

Key Laboratory of Macromolecular Synthesis and Functionalization of the Ministry of Education of China

Zhejiang University, Hangzhou 310027 (PR China)

DOI: $10.1002 / \mathrm{adfm} .200901943$ carbon single bonds. Because of electronic saturation of the single bonds, the olefinic or vinyl polymers are electrically inactive and have thus been commonly used as commodity materials in contemporary society.

Polymerizations of acetylenic monomers can generate polymers with $\pi$-conjugated carbon-carbon double bonds that are expected to be electronically active. Indeed, polyacetylene has been found to show metallic conductivity upon dopingthis seminal discovery has triggered much research activity in the utilization of alkynes as building blocks to construct functional polymers. ${ }^{[1]}$ As a result of the enthusiastic efforts of polymer chemists, a large number of acetylenic polymers have been synthesized. ${ }^{[2]}$ In almost all the acetylenic polymers, their monomer repeating units are strung together by carbon-carbon linkages. The polymerizations of acetylene monomers through carbon-heteroatom hookups are of great interest because the resultant heteroatom-containing acetylenic polymers may exhibit properties that are difficult, if not impossible, to access by the polymers with pure carbon-based skeletons.

Alkyne hydrothiolation is a reaction that is potentially useful for the synthesis of heteroatom-containing acetylenic polymers. The reaction was first reported by Truce and Simms in the 1950s: admixing alkynes with sodium thiolates resulted in the formation of vinyl sulfides. ${ }^{[3]}$ The extensive studies on alkyne hydrothiolations in the past half century have revealed that the reactions proceed through Markovnikov and anti-Markovnikov addition routes to produce regio- and stereoisomers with branched and linear structures (Scheme 1). ${ }^{[4,5]}$ One recent development in the area is the report by Yorimitsu and coworkers that certain cesium salts initiate hydrothiolations of aryl alkynes with alkyl thiols. ${ }^{[6]}$ The inorganic bases, however, was not applicable to aryl thiols, while organic bases such as triethylamine completely failed to work as catalysts when the reactions were attempted at room temperature.

It is envisioned that alkyne hydrothiolation of alkyne and thiol with two triple bonds (diyne) and mercapto groups (dithiol) may produce a poly(vinylenesulfide) (PVS) with linear and branched conformations. The sulfur-containing polymer may exhibit properties uniquely associated with its high sulfur content, such as high light refractivity and excellent optical transparency, and 


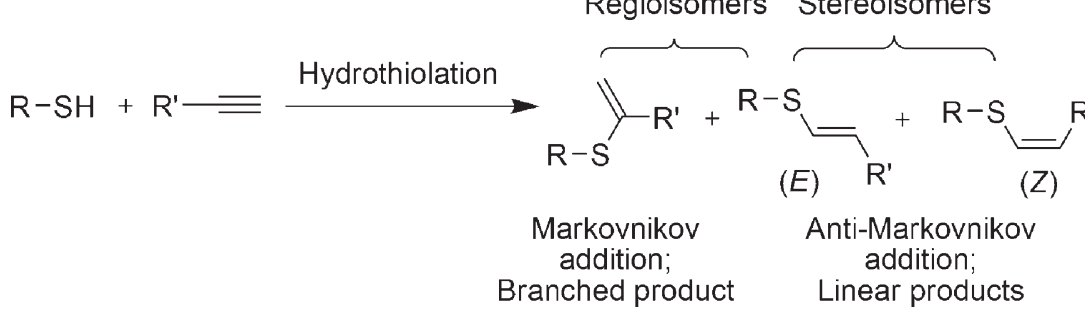

Scheme 1. Formation of 1,1- and 1,2-disubstituted olefins with branched and linear structures by Markovnikov and anti-Markovnikov routes of alkyne hydrothiolation, respectively. transparent and are readily metallized by complexation with cobalt carbonyls to furnish organometallic polymers with high refractive indexes $(n=2.106-1.708)$ and low chromatic aberrations ( $D^{\prime}$ down to 0.002 ).

\section{Results and Discussion}

\subsection{Monomer Preparation}

To explore the possibility of utilizing alkyne thus find high-tech applications as a promising photonic material. ${ }^{[7]}$ The PVS may readily react or coordinate with transition metals and the resultant macromolecular complexes may work as recyclable and reusable polymer catalysts ${ }^{[8]}$ and serve as processable precursors to non-oxide ceramics upon pyrolysis. ${ }^{[9]}$ Such possibilities, although attractive, have been virtually unexplored.

Our groups have been working on the development of alkyne polymerization reactions. Employing monoynes, diynes, and triynes as monomers, we have successfully synthesized a large variety of polyacetylenes, polyarylenes, polydiynes, and polytriazoles with linear and hyperbranched structures and regio- and stereoregularities by metathesis, cyclotrimerization, coupling, and click polymerizations. ${ }^{[10]}$ In our previously investigated click polymerization systems, azide-alkyne cycloaddition (or 'azidoclick') reactions were utilized. Thiol-alkene addition is another well-known click reaction and has been used by several research groups to synthesize saturated macromolecules such as dendrimers and star polymers. ${ }^{[11,12]}$ In contrast, thiol-alkyne addition or alkyne hydrothiolation remains unexploited, although it has the potential to be developed into a new "thioclick" polymerization technique for the synthesis of sulfur-containing unsaturated polymers.

In this work, we have extended our acetylene-based research to a heteroatom-mediated system and have developed alkyne hydrothiolation into a versatile polymerization technique for the preparation of sulfur-rich acetylenic polymers. In this paper, we show that alkyne polyhydrothiolations of 4,4'-thiodibenzenethiol (1) and arylene dipropiolates (2-5) are mediated by organobases such as secondary amines at room temperature to afford regioregular linear PVSs (P1/2-P1/5) with high molecular weights and high stereoregularities in high yields (Scheme 2). This represents the first example of a metal-free, organobase-mediated, thioclick polymerization reaction. The PVSs are optically

hydrothiolation to construct sulfur-containing macromolecules, we adopted an $\mathrm{A}_{2}+\mathrm{B}_{2}$ approach and used dithiol $\mathbf{1}$ and dipropiolates $2-5$ as building blocks for the synthesis of linear PVSs. The advantage of this strategy is that the monomers can be synthesized with ease and can be kept for a long time on the shelf under ambient conditions, which circumvents the self-oligomerization problem met by the $\mathrm{AB}_{2}$ approach.

Arylene dipropiolates 2-5 were prepared by esterifications of their corresponding diols with propiolic acid in the presence of 1,3 dicyclohexylcarbodiimide (DCC), 4-(dimethylamino)pyridine (DMAP), and p-toluenesulfonic acid (TsOH). All the monomers were characterized by spectroscopic techniques, from which satisfactory analysis data corresponding to their expected molecular structures were obtained (see Experimental section for details).

\subsection{Polymer Synthesis}

The development of non-metallic and metal-free polymerization reactions has attracted much interest among polymer chemists in recent years because of their remarkable advantages, such as environmental benignity, economic benefit, and ease in polymer purification. ${ }^{[13]}$ The reactions are free of the detrimental effects of metallic ions in the catalyst residues on polymer properties, such as light emission and optical non-linearity. In addition, functional groups that are toxic to transition metals can be used, which helps widen the variety of polymers that can be synthesized by the reactions.

In our previous investigations, we found that bis(aroylacetylene)s and dipropiolates could be polycyclotrimerized in the presence of secondary amines or in refluxing $N, N$-dimethylformamide (DMF). ${ }^{[10]}$ We thus tried to synthesize PVS from 1 and 3 under metal-free conditions. After stirring in DMF at room temperature for $24 \mathrm{~h}$, a PVS with an $M_{\mathrm{w}}$ of 5200 was isolated in a yield of $\sim 92 \%$ (Supporting Information, Table S1, run 1). Changing the solvent to tetrahydrofuran (THF), toluene, and dioxane had little effect on the yield of the PVS but decreased its molecular weight. Both yield and $M_{\mathrm{w}}$ dropped when the polymerization was preformed in 1,2dichlorobenzene.

In the presence of organobase, the nucleophilicity of the thiol group will be increased, which may enhance the efficiency of its 
Table 1. Effect of organobase on polyhydrothiolation of 1 and 3.

\begin{tabular}{lcccc}
\hline Run [a] & Base & Yield [\%] & $M_{\mathrm{w}}[\mathrm{b}]$ & $M_{\mathrm{w}} / M_{\mathrm{n}}[\mathrm{b}]$ \\
\hline 1 & piperidine & Gel & & \\
2 & methylpiperazine & Gel & & \\
3 & diethylamine & 37.0 & 17100 & 3.2 \\
4 & triethylamine & 71.7 & 6300 & 1.7 \\
5 & diphenylamine & 97.1 & 32300 & 1.9 \\
6 & triphenylamine & 97.1 & 6800 & 1.7 \\
7 & morpholine & 81.8 & 3900 & 1.7 \\
8 & diphenylamine & 97.8 & 30100 & 2.1 \\
\hline
\end{tabular}

[a] Carried out at room temperature in DMF under nitrogen for $24 \mathrm{~h}$; $[1]=[3]=0.06 \mathrm{M}$; [base] $=0.6 \mathrm{M}$ (except for run 8, where $[$ base $]=1.2 \mathrm{M}$ ).

[b] Estimated by gel permeation chromatography (GPC) in THF on the basis of a polystyrene calibration.

addition reaction. With this consideration in mind, we tested the effects of different amines on the alkyne polyhydrothiolation. Insoluble gels are formed when the polymerizations are initiated by piperidine and methylpiperazine (Table 1 , runs 1 and 2). Soluble polymers, however, are obtained in moderate to high yields when other amines are used. Among them, diphenylamine works efficiently for the reaction, producing a PVS with a high molecular weight $\left(M_{\mathrm{w}} 32300\right)$ in a nearly quantitative yield (97\%). Doubling the amount of diphenylamine to $1.2 \mathrm{M}$ gives similar results, because the thiol group of $\mathbf{1}$ is already converted into thiolate in the reaction mixture containing $0.6 \mathrm{~m}$ diphenylamine.

We then tried to determine the optimal monomer concentration $[\mathrm{M}]$ in the polymerization of $\mathbf{1}$ and $\mathbf{3}$ in the diphenylamine/DMF mixture. In all the runs, an equimolar ratio of 1 and 3 was used. With an increase in [M], the $M_{\mathrm{w}}$ of the polymer is enhanced and reaches its maximum value of $\sim 32000$ at $[M]=0.06 \mathrm{M}$ (Fig. 1). Further increasing $[\mathrm{M}]$ has an adverse effect on the molecular weight. The polymer yield remains high at all [M]s studied, which demonstrates of the high efficiency of the polymerization reaction.

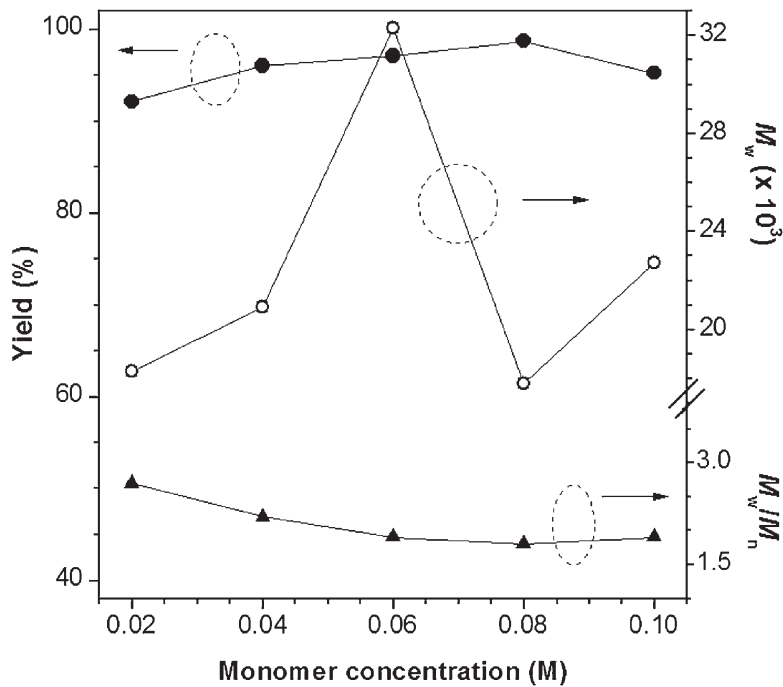

Figure 1. Effect of monomer concentration on the polyhydrothiolation of 1 and $\mathbf{3}$ at room temperature in DMF under nitrogen for $24 \mathrm{~h}$ in the presence of $1.2 \mathrm{M}$ of diphenylamine.

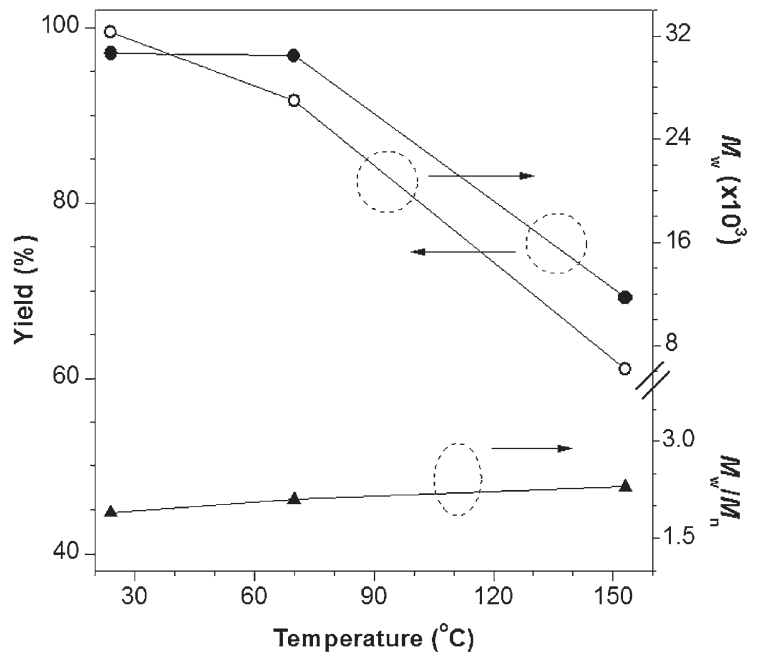

Figure 2. Effect of temperature on the polyhydrothiolation of $\mathbf{1}$ and $\mathbf{3}$ in DMF under nitrogen in the presence of $1.2 \mathrm{M}$ of diphenylamine for $24 \mathrm{~h}$; $[1]=[3]=0.06 \mathrm{M}$.

Temperature strongly influences the polymerization reaction. Both the yield and $M_{\mathrm{w}}$ of the PVSs are decreased when the temperature is raised from 23 to $150^{\circ} \mathrm{C}$ (Fig. 2). As mentioned above, dipropiolates can undergo polycyclotrimerization in refluxing DMF. ${ }^{[10]}$ Some portion of monomer 3 may selfpolymerize at high temperatures to form low-molecular-weight hyperbranched oligomers that may have been removed during the purification process of the reaction product. The concentration of 3 in the solution is thus lowered, which leads to the formation of polymers with lower molecular weights in lower yields. Figure 3 shows the time course of the alkyne polyhydrothiolation. After $12 \mathrm{~h}$, a polymer with a $M_{\mathrm{w}}$ of 25000 is obtained, which is high enough for practical applications. Prolonging the reaction time to

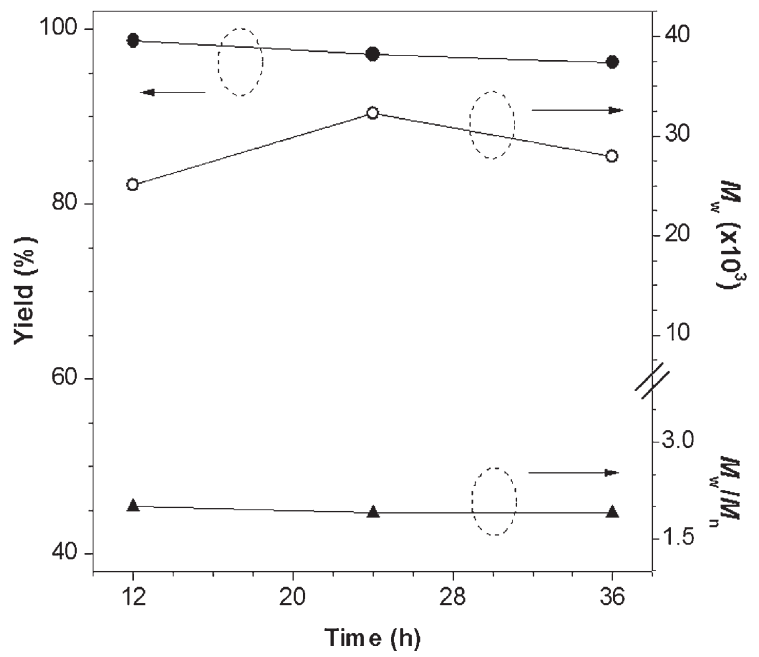

Figure 3. Time course of polyhydrothiolation of $\mathbf{1}$ and $\mathbf{3}$ at room temperature in DMF under nitrogen in the presence of $1.2 \mathrm{M}$ of diphenylamine; $[1]=[3]=0.06 \mathrm{M}$. 
Table 2. Polyhydrothiolation of 1 with $2-5$.

\begin{tabular}{lcccccc}
\hline Run [a] & Monomers & Yield [\%] & $S$ [b] & $M_{\mathrm{w}}[\mathrm{c}]$ & $M_{\mathrm{w}} / M_{\mathrm{n}}[\mathrm{c}]$ & $Z$ [d] [\%] \\
\hline $\mathbf{1}$ & $\mathbf{1 + 2}$ & 73.5 & $\sqrt{ }$ & 21000 & 2.9 & 78.1 \\
$2[\mathrm{e}]$ & $\mathbf{1}+\mathbf{3}$ & 97.2 & $\sqrt{ }$ & 29000 & 1.7 & 80.2 \\
3 & $\mathbf{1}+\mathbf{3}$ & 97.1 & $\sqrt{ }$ & 32300 & 1.9 & 81.4 \\
4 & $\mathbf{1}+\mathbf{4}$ & 87.2 & $\sqrt{ }$ & 7500 & 2.1 & 68.9 \\
5 & $\mathbf{1 + 5}$ & 98.2 & $\times$ & & & \\
\hline
\end{tabular}

[a] Carried out at room temperature in DMF in the presence of $1.2 \mathrm{M}$ diphenylamine under nitrogen for $24 \mathrm{~h}$ unless stated otherwise; [ monomer] $=0.06 \mathrm{M}$. [b] Solubility $(S)$ tested in common organic solvents such as toluene, DCM, chloroform, and THF: $\sqrt{ }=$ completely soluble, $x=$ insoluble. [c] Estimated by GPC in THF on the basis of a polystyrene calibration. [d] Determined by ${ }^{1} \mathrm{H}$ NMR spectroscopy. [a] Conducted in air.

$24 \mathrm{~h}$ slightly lowers the yield of the PVS but increases its $M_{\mathrm{w}}$ to 33000 .

The above systematic studies enable us to polymerize 1 with $2-5$ under optimal conditions. Table 2 summarizes the polymerization results. All the polymerizations proceed smoothly, giving P1/2$\mathrm{P} 1 / 5$ in good yields. Comparing the polymerization results of 1 and 3 obtained under nitrogen and in air, it is clear that oxygen and moisture exert little effect on the alkyne polyhydrothiolation reaction (Table 2, runs 2 and 3 ). The oxygen and moisture tolerances greatly help simplify the reaction procedures.

\subsection{Structural Characterization}

To verify that dithiol 1 and dipropiolates $2-5$ have indeed been polymerized in an alkyne polyhydrothiolation mechanism, we conducted a model reaction using thiophenol (6) and phenyl propiolate (7) as reactants (Scheme 3). While a thiol can undergo Markovnikov addition to an alkyne to give a branched vinyl sulfide, the reaction can also proceed in an anti-Markovnikov fashion to yield linear adducts with $E$ and $Z$ conformations (cf., Scheme 1). When $\mathbf{6}$ and 7 are reacted under conditions similar to those given in Table 2, run 2, product 8 is isolated in a high yield (94\%). Spectroscopic analysis reveals that 8 is a linear anti-Markovnikov product with a predominant $Z$ conformation $(Z: E=4: 1)$. No branched product is obtained at all, which indicates that the reaction proceeds in a regioselective fashion.

To collect direct structural information, we characterized the polymers by spectroscopic methods. Examples of the IR spectra of $\mathrm{P} 1 / 3$ and its monomers $\mathbf{1}$ and $\mathbf{3}$ are given in Figure 4. The $\mathrm{S}-\mathrm{H}$ stretching vibration of 1 is observed at $2600 \mathrm{~cm}^{-1}$, while the $=\mathrm{C}-\mathrm{H}$ and $\mathrm{C}=\mathrm{C}$ stretchings of 3 occur at 3266 and $2124 \mathrm{~cm}^{-1}$,

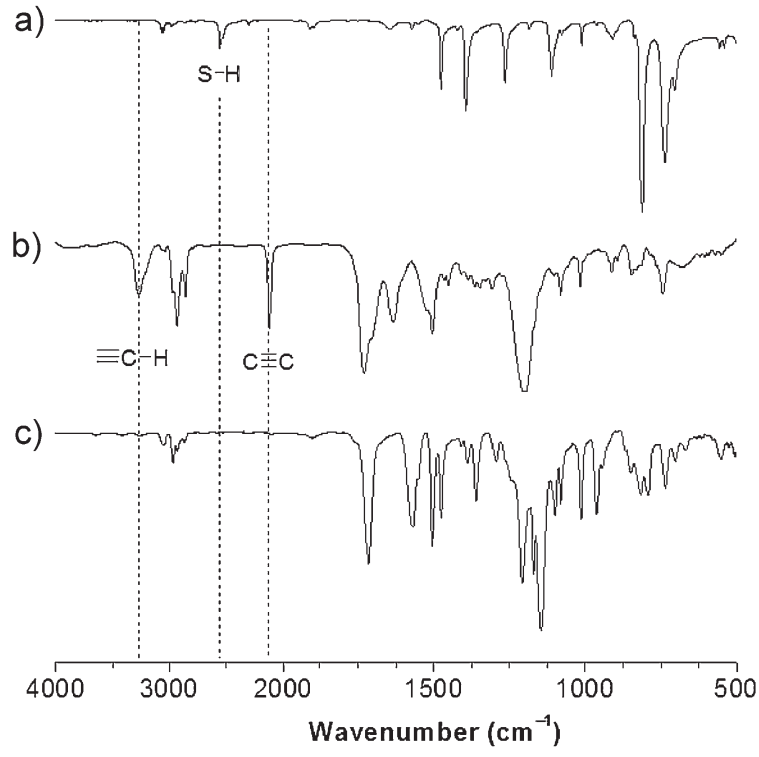

Figure 4. IR spectra of monomers a) $\mathbf{1}$, b) $\mathbf{3}$, and c) their polymer P1/3.

respectively. No such peaks are observed in the spectrum of $\mathrm{P} 1 / 3$. Instead, new peaks associated with $\mathrm{C}=\mathrm{C}$ stretching and bending vibrations are observed at 1580 and $940 \mathrm{~cm}^{-1}$, and reveal that all the mercapto groups and triple bonds of 1 and 3 have been transformed by the polymerization reaction into vinyl sulfide units in $\mathrm{P} 1 / 3$.

The model reaction suggests that the alkyne polyhydrothiolation is regioselective. To prove whether this is the real case, we analyzed the NMR spectra of the polymers. Figure 5 shows the ${ }^{1} \mathrm{H}$ NMR spectra of P1/3 and its monomers 1 and 3 in chloroform$d$; for better peak assignment, the spectrum of model compound 8 is also given in the figure. The thiol and acetylene protons of 1 and 3 resonate at $\delta 3.46$ and 3.06 , respectively, which completely disappear after the monomers have been subjected to alkyne polyhydrothiolation reaction. By comparison with the spectra of monomers 1 and 3 and model compound 8 , the resonance peaks in the spectrum of $\mathrm{P} \mathbf{1} / \mathbf{3}$ can be readily assigned. The resonances of the phenyl protons in $\mathrm{P} \mathbf{1} / \mathbf{3}$ are located at similar chemical shifts to those in 1 and 3.

New peaks assigned to the proton resonances of the linear vinyl groups newly formed by the alkyne polyhydrothiolation are observed at $\delta 5.86,6.15$, and 7.92. While the first and third peaks stem from the resonances of the PVS segments with an $E$-conformation, the second one originates from the resonance of the chain segments that comprise $Z$-isomeric units. Thanks to the large difference in the chemical shifts of the stereoisomers, the

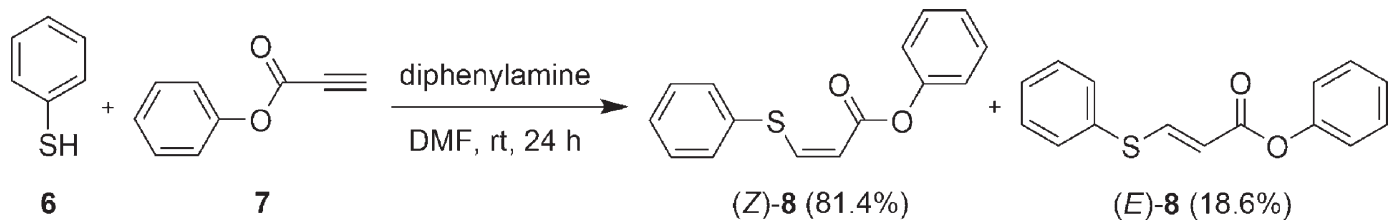

Scheme 3. Synthesis of model compound 8 with high stereoselectivity $(Z: E=4: 1)$ through organobase-catalyzed regioselective alkyne hydrothiolation. 


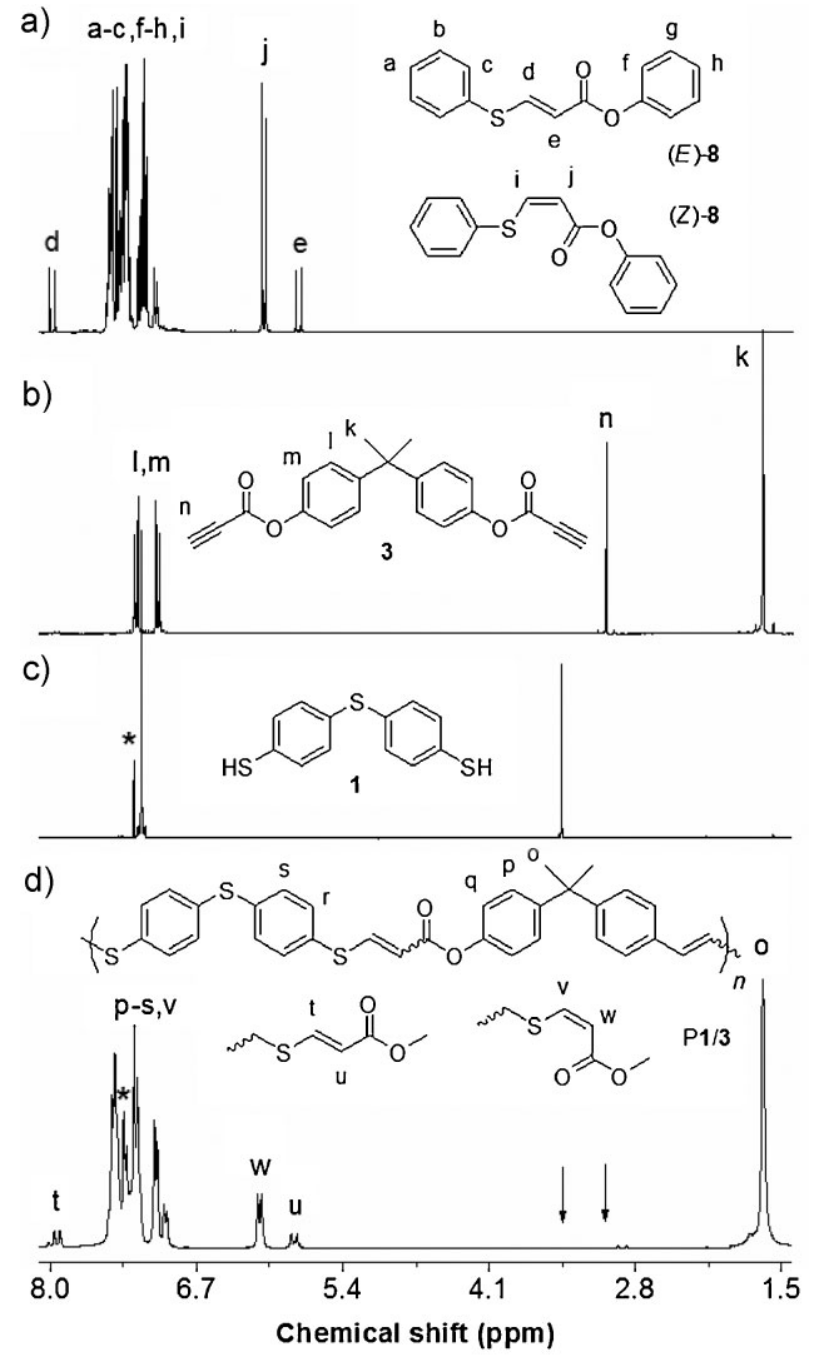

Figure 5. 'H NMR spectra of a) model compound 8, b) monomer 3, c) monomer 1 , and d) polymer $\mathrm{P} 1 / 3$ in $\mathrm{CDCl}_{3}$. The solvent peaks are marked with asterisks.

$E$ and $Z$ contents of the polymer can be calculated using their integrals and the $Z / E$ ratio is found to be $81.4 \%$. Other polymers are also Z-rich. Evidently, the alkyne polyhydrothiolation produces polymers with high stereoregularity.

The ${ }^{13} \mathrm{C}$ spectrum of $\mathrm{P} 1 / 3$ shows no resonance peaks of the acetylenic carbons of monomer 3 at $\delta 76.6$ and 74.3 (Supporting Information, Fig. S1). New peaks that correspond to the resonances of the olefinic carbons are observed at $\delta 164.8$, $163.5,115.0$, and 112.8 , because of the conversion of the acetylene triple bonds in 3 into the double bonds in P1/3.

\subsection{Solubility and Stability}

Except for P1/5, all other polymers are completely soluble in common organic solvents, such as toluene, dichloromethane,
Table 3. Thermal properties of $\mathrm{P} 1 / 2-\mathrm{P} 1 / 5$ determined by thermogravimetric analysis under nitrogen at a heating rate of $10^{\circ} \mathrm{C} \mathrm{min}^{-1}$.

\begin{tabular}{lccc}
\hline Polymer & $F_{\mathrm{S}}[\mathrm{a}][\mathrm{wt} \%]$ & $T_{\mathrm{d}}[\mathrm{b}]\left[{ }^{\circ} \mathrm{C}\right]$ & $W_{\mathrm{r}}[\mathrm{c}][\%]$ \\
\hline $\mathrm{P} 1 / 2$ & 13.38 & 345 & 45.6 \\
$\mathrm{P} 1 / 3$ & 16.51 & 335 & 42.0 \\
$\mathrm{P} 1 / 4$ & 21.21 & 324 & 14.1 \\
$\mathrm{P} 1 / 5$ & 22.39 & 333 & 32.9 \\
\hline
\end{tabular}

[a] Sulfur content of PVS calculated from its repeat unit. [b] Temperature for $5 \%$ weight loss. [c] $W_{r}=$ weight residue at $600^{\circ} \mathrm{C}$.

chloroform, THF, and dioxane, and can be readily fabricated into tough solid films by spin-coating and static-casting processes. Among the PVSs, P1/5 has the highest sulfur content $\left(F_{\mathrm{S}}>22 \mathrm{wt} \%\right.$; Table 3). Its intractability may thus be caused by the strong interaction between the sulfur atoms in different polymer chains, which leads to the formation of physical crosslink networks. This hypothesis is further supported by the good solubility of its sulfonylated counterpart of P1/4. The oxidation of the thio group between the phenyl rings reduces the likelihood of the formation of a disulfur bridge between the polymer chains, thus making P1/ 4 soluble in common organic solvents.

All the polymers are thermally stable. As can be seen from Fig. S2 in the Supporting Information, the temperatures for 5\% weight loss or the degradation temperatures $\left(T_{\mathrm{d}}\right)$ of the polymers are all higher than $320^{\circ} \mathrm{C}$ under nitrogen, which is indicative of their strong resistance to thermolysis (Table 3). Except for P1/4, the residues of the polymers after pyrolysis at $600^{\circ} \mathrm{C}$ are higher than $30 \%$. The exceptionally low weight residue for P1/4 ( 14 wt \%) is probably a result of the ready evaporation of the sulfur dioxide gas formed in the pyrolysis process of the sulfonylated polymer at the high temperature.

\subsection{Metal Complexation}

The polymers contain $\pi$-electron-rich aromatic rings and vinyl double bonds as well as metal-affinitive or metallophilic thio groups that are expected to form organometallic complexes with cobalt carbonyls. ${ }^{[14]}$ Indeed, when the soluble PVSs (P1/2, P1/3, and $\mathrm{P} 1 / 4)$ are admixed with $\mathrm{Co}_{2}(\mathrm{CO})_{8}$ in THF, their solutions are darkened, which is accompanied by gas evolution. The solutions remain homogeneous throughout the whole process of the cobaltcomplexation reaction. However, the isolated macromolecular complexes P1/2(Co)-P1/4(Co) are insoluble, possibly because of the formation of supramolecular aggregates during the product purification processes (precipitation into poor solvent and drying under vacuum).

We used elemental analysis (EA) and energy-dispersion X-ray analysis (EDX) to estimate the compositions of the PVS(Co) complexes. The cobalt contents of P1/2(Co), P1/3(Co), and P1/ $4(\mathrm{Co})$ determined by EA are $0.09,6.25$, and $1.86 \%$, respectively (Table 4). The severe steric effect of the bulky, non-planar tetraphenylethene (TPE) units in P1/2 may have greatly shielded the vinyl sulfide groups and hampered them from reacting with $\mathrm{Co}_{2}(\mathrm{CO})_{8}$. On the other hand, the higher $M_{\mathrm{w}}$ value of $\mathrm{P} 1 / 3$ together 
Table 4. Chemical compositions of PSV(Co)s in units of at \%.

\begin{tabular}{lcccccccccc}
\hline $\begin{array}{l}\text { Polymer } \\
\text { complex }\end{array}$ & \multicolumn{3}{c}{ EA } & \multicolumn{1}{c}{ EDX } & \multicolumn{3}{c}{ XPS } \\
\cline { 2 - 10 } & C & H & Co & C & O & Co & C & O & Co \\
\hline $\mathrm{P} 1 / 2(\mathrm{Co})$ & 72.95 & 3.92 & 0.09 & 85.85 & 2.72 & 0.16 & 83.99 & 8.59 & 0.12 \\
$\mathrm{P} 1 / 3(\mathrm{Co})$ & 67.46 & 4.41 & 6.25 & 71.97 & 7.55 & 8.33 & 80.88 & 10.76 & 2.02 \\
$\mathrm{P} 1 / 4(\mathrm{Co})$ & 59.18 & 3.33 & 1.86 & 65.78 & 3.93 & 1.62 & 73.70 & 15.73 & 0.87 \\
\hline
\end{tabular}

with its less sterically hindered bisphenol-A moieties may have enabled more efficient metal complexations, which leads to the higher cobalt content in its complex. Similar results are obtained from the EDX measurements.

The analysis by X-ray photoelectron spectroscopy (XPS) offers information about chemical compositions on the surfaces of PVS(Co) powders. The cobalt contents estimated by the XPS analysis are generally lower than those obtained from the EA and EDX analyses, which suggests that the cobalt species are aggregated in the bulk rather than on the surface. The ceramic materials obtained from the pyrolyses of the PVS(Co) complexes are practically non-magnetic, in sharp contrast to the very high magnetizabilities of the ceramics obtained from the cobalt complexes of the hyperbranched polymers in our previous studies. ${ }^{[9]}$ This is probably because of the formation of cobalt sulfides $\mathrm{Co}_{x} \mathrm{~S}_{\gamma}$ by the pyrolysis of the PSV(Co) complexes, which are known to be magnetically insusceptible. ${ }^{[15]}$

\subsection{Optical Transparency}

Polymers with high optical clarity are promising candidate materials for advanced photonic applications. ${ }^{[16]}$ The PVSs absorb little light in the visible spectroscopic region and allows almost all the light at wavelengths longer than $400 \mathrm{~nm}$ to transmit through (Fig. 6). For example, the light transmittance of P1/3 is already $99 \%$ at a wavelength as short as $370 \mathrm{~nm}$. Although the optical transparencies of the polymers are decreased after complexation with cobalt metal, the light transmittances are still higher than $90 \%$ beyond $400 \mathrm{~nm}$. For example, the light transmittance of P1/3(Co) at $370 \mathrm{~nm}$ is $98 \%$, just $1 \%$ lower than that of its parent form (P1/3). The excellent transparencies of the PVSs and PVS(Co)s may be attributed to the existence of two ester groups in every one of their repeat units, which weaken the electronic communications between the neighboring aromatic and vinyl groups, thereby decreasing their absorptivities in the long wavelength region.

\subsection{Light Refractivity}

The PVSs are comprised of polarizable aromatic rings, ester groups, and sulfur atoms and may show high refractive indices. ${ }^{[17]}$ This is indeed the case: as shown in Figure 7a, P1/2 displays high refractivities $(n=1.7300-1.6569)$ over a wide spectroscopic region (500-1700 nm). Polymers P1/3 and P1/4 display similarly high refractive indexes of 1.7148-1.6611 and 1.7345-1.7003, respectively, in the same spectroscopic region. It is noted that the $n$ value

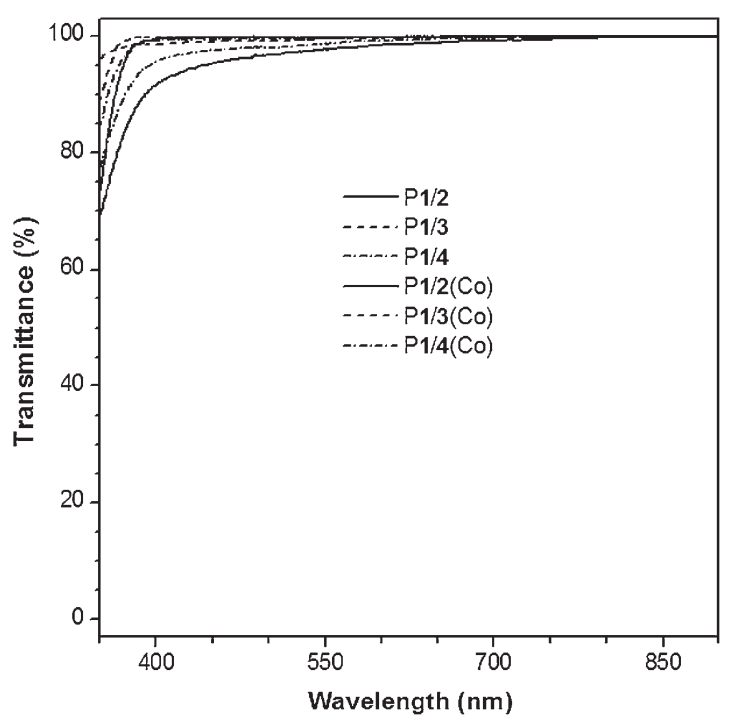

Figure 6. Light transmission spectra of THF solutions of $\mathrm{P} 1 / 2-\mathrm{P} 1 / 4$ and thin solid films of $\mathrm{P} 1 / 2(\mathrm{Co})-\mathrm{P} \mathbf{1} / \mathbf{4}(\mathrm{Co})$. Solution concentration $\left(\mu \mathrm{g} \mathrm{mL}^{-1}\right)$ : 7.2 (for $\mathrm{P} 1 / 2$ ), 5.7 (for $\mathrm{P} 1 / 3$ ), 6.0 (for $\mathrm{P} 1 / 4$ ).
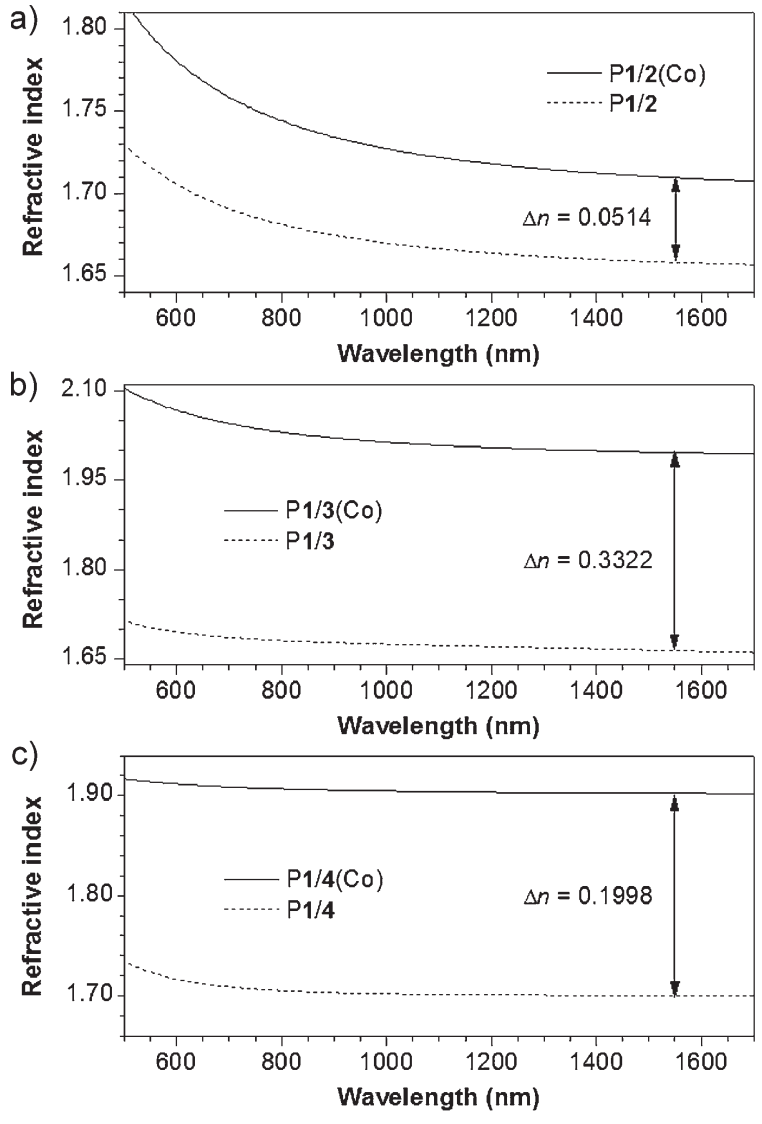

Figure 7. Wavelength dependence of refractive indexes of thin films of a) $\mathrm{P} 1 / 2$ and $\mathrm{P} 1 / 2$ (Co), b) $\mathrm{P} 1 / 3$ and $\mathrm{P} 1 / 3$ (Co), and c) $\mathrm{P} 1 / 4$ and $\mathrm{P} 1 / 4(\mathrm{Co}) ; \Delta n$ values given in the figures are the differences in the refractive indexes at $1550 \mathrm{~nm}$. 
Table 5. Refractive indices and chromatic dispersions of PVSs and PSV(Co)s.

\begin{tabular}{lccrrrr}
\hline Film [a] & $n_{632.8}$ & $n_{1550}$ & \multicolumn{1}{c}{$\nu_{\mathrm{D}}$} & \multicolumn{1}{c}{$\nu_{\mathrm{D}}{ }^{\prime}$} & \multicolumn{1}{c}{$D$} & $D^{\prime}$ \\
\hline $\mathrm{P} 1 / 2$ & 1.7004 & 1.6583 & 18.4 & 70.4 & 0.054 & 0.014 \\
$\mathrm{P} 1 / 3$ & 1.6918 & 1.6640 & 22.8 & 69.6 & 0.044 & 0.014 \\
$\mathrm{P} 1 / 4$ & 1.7317 & 1.7004 & 26.3 & 539.0 & 0.038 & 0.002 \\
$\mathrm{P} 1 / 2(\mathrm{Co})$ & 1.7728 & 1.7097 & 13.6 & 50.7 & 0.074 & 0.020 \\
$\mathrm{P} 1 / 3(\mathrm{Co})$ & 2.0593 & 1.9962 & 18.6 & 80.0 & 0.054 & 0.014 \\
$\mathrm{P} 1 / 4(\mathrm{Co})$ & 1.9166 & 1.9002 & 156.5 & 643.0 & 0.006 & 0.002 \\
\hline
\end{tabular}

[a] Abbreviations: $n=$ refractive index, $\nu_{\mathrm{D}}=$ Abbé number (calculated from equation 1), $\nu_{\mathrm{D}}$ ' = modified Abbé number (calculated from equation 2 ), $D=$ chromatic dispersion in the visible region, and $D^{\prime}=$ chromatic dispersion in the IR region.

increases with the sulfur content $\left(F_{S}\right)$ in the polymer (cf., Table 3). When the $F_{\mathrm{S}}$ value is increased from $\sim 13 \%$ in P1/2 to 21\% in P1/ 4 , the $n$ value at $1550 \mathrm{~nm}$ is increased from 1.6583 to 1.7004 . The refractivity of the PVS can thus be tuned through molecular engineering endeavors. P1/5 has the highest sulfur content among the polymers but unfortunately its refractivity cannot be measured because of its insolubility in common organic solvents.

The $n$ values of $\mathrm{P} 1 / 2, \mathrm{P} 1 / 3$, and $\mathrm{P} 1 / 4$ are around 1.7 at $632.8 \mathrm{~nm}$ and larger than 1.65 even at $1550 \mathrm{~nm}$ (Table 5), which are much higher than those of the commercially important optical plastics [e.g., $n \sim 1.49$ for poly(methyl methacrylate) (PMMA) and $n \sim 1.59$ for poly(ethylene terephthalate) (PET) and polycarbonate (PC)]. The PVSs are thus highly refractive polymers. No or little birefringence is detected, which is indicative of the amorphous nature of their thin solid films.

Interestingly, after metal complexation, the $n$ values of the polymers are further enhanced (up to 2.0593). Inorganic and organometallic materials often show higher refractive indexes than pure organic materials. ${ }^{[17,18]}$ The high refractive indexes of PSV(Co)s are thus likely because of their metallic components. The differences in the refractivity $(\Delta n)$ between PVSs and PVS(Co)s at the telecommunication important wavelength of $1550 \mathrm{~nm}$ can be as large as 0.3322 (Fig. $7 \mathrm{~b}$ ). The $\Delta n$ value of the $\mathrm{P} 1 / 2$ and $\mathrm{P} 1 / 2$ (Co) pair is relatively small (0.0514), which is understandable because of the low cobalt content in $\mathrm{P} 1 / 2(\mathrm{Co})$.

\subsection{Chromatic Dispersion}

For a material to be useful for practical applications, its optical aberrations should be small. The Abbé number $\left(v_{\mathrm{D}}\right)$ of a material is a measure of the variation or dispersion in its refractive index with wavelength, which is defined as

$v_{\mathrm{D}}=\frac{n_{\mathrm{D}}-1}{n_{\mathrm{F}}-n_{\mathrm{C}}}$

where $n_{\mathrm{D}}, n_{\mathrm{F}}$, and $n_{\mathrm{C}}$ are the refractive indexes at wavelengths of the Fraunhofer D, F, and C spectroscopic lines of 589.2, 486.1, and $656.3 \mathrm{~nm}$, respectively. A modified Abbé number $\left(v_{\mathrm{D}}^{\prime}\right)$ has been proposed to evaluate the application potential of an optical material, using its $n$ values at the non-absorbing wavelengths of 1064, 1319, and $1550 \mathrm{~nm} .{ }^{[19]}$ The first two wavelengths are chosen in view of the practical interest of a commercial laser wavelength (Nd:YAG), while the last one is the wavelength of telecommunication importance. The modified Abbé number is defined as

$v_{\mathrm{D}}^{\prime}=\frac{n_{1319}-1}{n_{1064}-n_{1559}}$

where $n_{1319}, n_{1064}$, and $n_{1550}$ are the refractive indexes at 1319 , 1064 , and $1550 \mathrm{~nm}$, respectively. The chromatic dispersion $\left(D^{\prime}\right)$ is the constringence of the Abbé number $\left(v_{\mathrm{D}}{ }^{\prime}\right)$ :

$D^{\prime}=\frac{1}{v_{\mathrm{D}}^{\prime}}$

The $v_{\mathrm{D}}$ and $v_{\mathrm{D}}^{\prime}$ values of $\mathrm{P} 1 / 4$ are 26.3 and 643, which correspond to $D$ and $D^{\prime}$ values of 0.038 and 0.002 , respectively (Table 5). After metal complexation, the $D$ and $D^{\prime}$ values of P1/ 4 (Co) drop to 0.006 and 0.002 , respectively, which are lower than those of PC $(D=0.0297)$ and PMMA $(D=0.0175),{ }^{[20]}$ and are comparable to our recently synthesized poly(triazole)s by the metal-free azido-click polymerizations $\left(D^{\prime}=0.006-0.004\right){ }^{[10]}$ Other PVS(Co)s also show small chromatic dispersions. The low spectroscopic aberrations of the polymers, coupled with their high optical transparencies and light refractivities, may enable them to find technological applications as coating materials in advanced optical display systems, such as microlens components for charge-coupled devices and high-performance complementary metal-oxide semiconductor image sensors. ${ }^{[7]}$

\subsection{Photoresponsive Patterning}

The PVSs contain a large number of photosensitive vinyl and ester groups. The polymers may be readily photo-crosslinked because of the formation of free radicals by UV irradiation and can thus be used as negative photoresist materials for pattern generation. ${ }^{\text {[21] }}$ When a thin solid film of $\mathrm{P} 1 / 2$ spin-coated on a silicon wafer is irradiated in air through a copper photomask, the exposed region of the thin film is readily photo-crosslinked and a negative photoresist pattern with clear-cut edges is generated after the development of the irradiated polymer film by 1,2-dichloroethane (Fig. 8).

The TPE moieties in the backbone of P1/2 are well-known luminogenic units that exhibit an unusual phenomenon of aggregation-induced emission (AIE). ${ }^{[22,23]}$ Although light emission of a 'conventional' luminophore is often quenched when its molecules are aggregated in the solid state and fabricated into a thin film, the film of $\mathrm{P} 1 / 2$ is still luminescent, thanks to its unique AIE feature. The photopattern generated by the photolysis of P1/2 emits a yellow light upon illumination with a handheld UV lamp, as evidenced by the luminescence image taken under a fluorescence microscope shown in Figure 8. Clearly, the polymer can be used as a photoresist material for the creation of fluorescent images. 

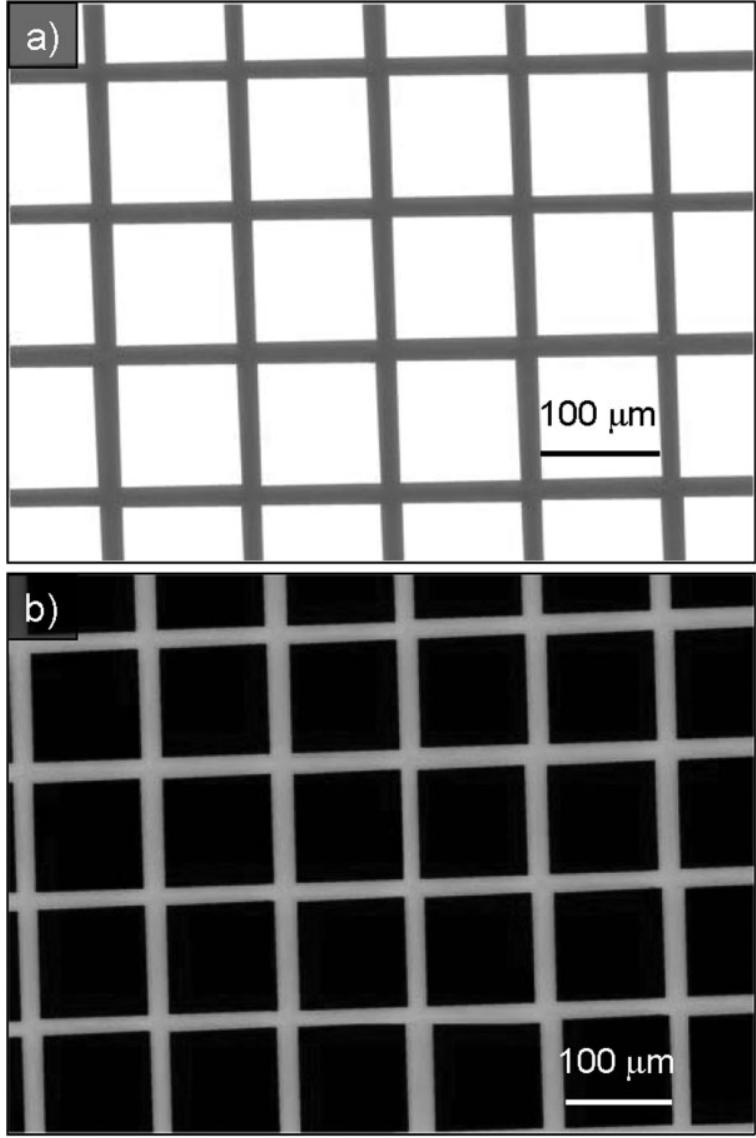

Figure 8. Negative photoresist pattern generated by photolithography of P1/2; photographs taken under a) room lighting and b) UV illumination.

\section{Conclusions}

In this work, we have developed a thioclick polymerization technique for the synthesis of heteroatom-containing acetylenic polymers. The alkyne polyhydrothiolations of dithiol 1 and dipropiolates 2-5 proceed smoothly in the presence of diphenylamine at room temperature, producing sulfur-rich polymers P1/ 2-P1/5 with high molecular weights in high yields. The organobase-mediated alkyne hydrothiolation reaction is strictly regioselective and furnishes polymers with high stereoregularities. The polymerization reaction is tolerant to functional groups as well as air and moisture. All these advantageous attributes make the alkyne polyhydrothiolation a true click reaction. ${ }^{[1]}$

Polymers P1/2-P1/4 are completely soluble, film-forming, thermally stable, and optically transparent. Their films exhibit high refractive indices and low chromatic aberrations. Their refractivities can be tuned by their sulfur contents and greatly enhanced by complexation with transition-metal compounds such as cobalt carbonyls. The PVSs are photoresponsive and their films can be readily photo-crosslinked to create negative photoresist patterns that emit strong visible light upon photoexcitation. These unique features make the polymers promising photonic materials for high-tech applications.

\section{Experimental}

Materials: THF (Labscan), toluene (BDH), and dioxane (Aldrich) were distilled under nitrogen from sodium benzophenone ketyl immediately prior to use. Dichloromethane was distilled under nitrogen over calcium hydride. DMF was stirred with calcium hydride overnight, distilled under reduced pressure, and kept under nitrogen. Other solvents, such as triethylamine and dimethyl sulfoxide (DMSO), were purified using standard procedures. All the chemicals used in this work, such as $4,4^{\prime}$. thiodibenzenethiol (1), were purchased from Aldrich and used as received without further purification. 1,2-Bis (4-hydroxyphenyl)-1,2-diphenylethene was prepared according to our previously published procedures [23b].

Instrumentation: IR spectra were recorded on a Perkin-Elmer 16 PC FTIR spectrophotometer. ${ }^{1} \mathrm{H}$ and ${ }^{13} \mathrm{C}$ NMR spectra were measured on Bruker ARX 300 NMR spectrometers using $\mathrm{CDCl}_{3}$ or DMSO- $d_{6}$ as solvents. Light transmission spectra were measured on a Milton Roy Spectronic 3000 array spectrophotometer. MALDI-TOF spectra were recorded on a GCT Premier CAB048 mass spectrometer operating in a chemical ionization $(\mathrm{Cl})$ mode with methane as carrier gas. $M_{\mathrm{w}}, M_{\mathrm{n}}$, and $M_{\mathrm{w}} / M_{\mathrm{n}}$ values of the polymers were estimated by a Waters Associates GPC system equipped with refractive index (RI) and UV detectors. THF was used as eluent at a flow rate of $1.0 \mathrm{~mL} \mathrm{~min}^{-1}$. A set of monodisperse linear polystyrenes were used as standards for the molecular weight calibration.

EA experiments were conducted on an Elementary Vario EL analyzer. XPS measurements were conducted on a $\mathrm{PHI} 5600$ spectrometer (Physical Electronics), and the core level spectra were measured using a monochromatic Al K $\alpha$ X-ray source $(h v=1486.6 \mathrm{eV})$. The analyzer was operated at $23.5 \mathrm{eV}$ pass energy and the analyzed area was $800 \mu \mathrm{m}$ in diameter. EDX analyses were preformed on a JEOL-6300 SEM system with quantitative elemental mapping and line scan capacities operating at an accelerating voltage of $15 \mathrm{kV}$. Thermogravimetric analyses (TGA) were carried out under nitrogen on a Perkin-Elmer TGA 7 analyzer at a heating rate of $10^{\circ} \mathrm{C} \mathrm{min}^{-1}$

Refractive indices of the polymers were determined on a J. A. Woollam variable angle ellipsometry system with a wavelength tunable from 300 to $1700 \mathrm{~nm}$. To fit the acquired $\Psi$ and $\Delta$ curves with the data obtained from the three-layer optical model that consisted of a crystalline silicon substrate, a $2 \mathrm{~nm}$ silicon dioxide layer, and a uniform polymer film, the Levenberg-Marquardt regression algorithm was employed. The Cauchy dispersion law was applied to describe the polymer layer from the visible to the IR spectroscopic region.

Monomer Preparation: Dipropiolates 2-4 were prepared by the esterification reactions of propiolic acid with 1,2-bis(4-hydroxyphenyl)1,2-diphenylethene, bisphenol A, 4,4'-sulfonyl diphenol, and 4,4'-thiodiphenol, respectively. The synthetic procedures were similar to those described in our previous publications [10c].

Characterization Data for 4,4'-(1,2-Diphenylethenylene)diphenyl Dipropiolate (2): White solid; yield 63.5\%. IR (thin film) $v=3276,3054$, 2934, 2856, 2124, 1732, 1650, $1502 \mathrm{~cm}^{-1}$. ${ }^{1} \mathrm{H} \mathrm{NMR}\left(300 \mathrm{MHz}, \mathrm{CDCl}_{3}\right.$ TMS, $\delta): 8.04(\mathrm{~s}, 1 \mathrm{H}), 8.05(\mathrm{~s}, 1 \mathrm{H}), 6.91(\mathrm{t}, 4 \mathrm{H}), 7.02(\mathrm{~m}, 8 \mathrm{H}), 7.11(\mathrm{~m}, 6 \mathrm{H})$. ${ }^{13} \mathrm{C}$ NMR $\left(75 \mathrm{MHz} \mathrm{CDCl}_{3}, \mathrm{TMS}, \delta\right): 150.71,148.25,142.89,141.77,140.46$ 132.23, 131.21, 129.45, 128.47, 127.76, 126.77, 120.39, 94.08, 76.83, 76.65 74.15. HRMS (MALDI-TOF, $m / z$ ): $[\mathrm{M}+\mathrm{H}]^{+}$calcd for $\mathrm{C}_{32} \mathrm{H}_{21} \mathrm{O}_{4}, 469.4988$; found, 469. 1034. Anal. calcd for $\mathrm{C}_{32} \mathrm{H}_{20} \mathrm{O}_{4}$ : C 82.04, H 4.30; found: $\mathrm{C} 82.00$, $\mathrm{H} 4.50$.

Characterization Data for 4,4'-Isopropylidenediphenyl Dipropiolate (3): White solid; yield 53.2\%. IR (thin film), $v=3266,2934,2124,1730$ $1634 \mathrm{~cm}^{-1}$. ${ }^{7} \mathrm{H}$ NMR $\left(300 \mathrm{MHz}, \mathrm{CDCl}_{3}, \mathrm{TMS}, \delta\right): 7.26(\mathrm{~d}, 2 \mathrm{H}), 7.05$ (d, 2H), $3.06(\mathrm{~s}, 1 \mathrm{H}), 1.67(\mathrm{~s}, 3 \mathrm{H}) .{ }^{13} \mathrm{C}$ NMR $\left(75 \mathrm{MHz} \mathrm{CDCl}_{3}, \mathrm{TMS}, \delta\right): 151.0,148.5$, 147.7, 127.9, 120.6, 76.6, 74.3, 42.6, 30.8. HRMS (MALDI-TOF, $m / z$ ): $[\mathrm{M}+\mathrm{H}]^{+}$calcd for $\mathrm{C}_{21} \mathrm{H}_{17} \mathrm{O}_{4}, 333.3493$; found, 333.1080. Anal. calcd for $\mathrm{C}_{21} \mathrm{H}_{16} \mathrm{O}_{4}$ : C 75.89, $\mathrm{H} 4.85$; found: C 75.17, $\mathrm{H} 5.01$.

Characterization Data for 4,4'-Sulfonyldiphenyl Dipropiolate (4): White solid; yield 62.3\%. IR (thin film) $v=3268,2126,1734,1656,1588,1490$ $1410,1324,1294 \mathrm{~cm}^{-1}$. ' H NMR $\left(300 \mathrm{MHz}\right.$, DMSO- $\left.d_{6}, \mathrm{TMS}, \delta\right): 8.20(\mathrm{~d}$, $2 \mathrm{H}), 7.66(\mathrm{~d}, 2 \mathrm{H}), 5.03(\mathrm{~s}, 1 \mathrm{H}) .{ }^{13} \mathrm{C}$ NMR $\left(75 \mathrm{MHz}\right.$, DMSO- $\left.d_{6}, \mathrm{TMS}, \delta\right)$ : 153.2, 150.0, 139.0, 129.7, 123.4, 82.3, 74.0. HRMS (MALDI-TOF, $\mathrm{m} / \mathrm{z}$ ): $[\mathrm{M}+\mathrm{H}]^{+}$calcd for $\mathrm{C}_{18} \mathrm{H}_{11} \mathrm{O}_{6} \mathrm{~S}, 355.6681$; found, 355.3334. Anal. calcd for $\mathrm{C}_{18} \mathrm{H}_{10} \mathrm{O}_{6} \mathrm{~S}$ : C 61.01, H 2.84; found: C 61.62, H 3.05 . 
Characterization Data for 4,4'-Thiodiphenyl Dipropiolate (5): Pale yellow solid; yield 57.3\%. IR (thin film) $v=3273,2934,2126,1732,1585$, $1487 \mathrm{~cm}^{-1}$. ' $\mathrm{H}$ NMR (300 MHz, CDCl 3 , TMS, $\left.\delta\right): 7.37$ (d, 2H), 7.13 (d, 2H), $3.90(\mathrm{~s}, 1 \mathrm{H}) .{ }^{13} \mathrm{C} \mathrm{NMR}\left(75 \mathrm{MHz}, \mathrm{CDCl}_{3}, \mathrm{TMS}, \delta\right): 150.6,149.0,135.8$, 132.3, 122.8, 77.1, 74.0. HRMS (MALDI-TOF, $\mathrm{m} / \mathrm{z}$ ): $[\mathrm{M}+\mathrm{H}]^{+}$calcd for $\mathrm{C}_{18} \mathrm{H}_{11} \mathrm{O}_{4} \mathrm{~S}$, 323.3346; found, 323.0307. Anal. calcd for $\mathrm{C}_{18} \mathrm{H}_{10} \mathrm{O}_{4} \mathrm{~S}$ : C 67.07, H 3.13; found: C 67.07, H 3.65 .

Polymer Synthesis: All the polymerization reactions were carried out under dry nitrogen using a standard Schlenk technique, unless otherwise specified. A typical procedure for the polymerization of $\mathbf{1}$ and $\mathbf{2}$ is given below as an example. In a $15 \mathrm{~mL}$ Schlenk tube with a three-way stopcock on the sidearm was placed $40 \mathrm{mg}$ of $1(0.15 \mathrm{mmol})$ and $70 \mathrm{mg}$ of 2 $(0.15 \mathrm{mmol})$ under nitrogen in a glovebox. Diphenylamine $(0.5 \mathrm{~g}, 3 \mathrm{mmol})$ and DMF $(2.5 \mathrm{~mL})$ were added to dissolve the monomers using a hypodermic syringe. After stirring at room temperature for $24 \mathrm{~h}$, the mixture was added dropwise to about $300 \mathrm{~mL}$ of a hexane/diethyl ether $(v / v, 1: 1)$ mixture through a cotton filter under stirring. The precipitate was allowed to stand overnight and then collected by filtration. The product was washed with the hexane/diethyl ether mixture and dried under vacuum at room temperature to a constant weight.

Characterization Data for P1/2: White powder; yield 73.5\%. $M_{\mathrm{w}} 21000$, $M_{\mathrm{w}} / M_{\mathrm{n}} 2.9$ (GPC, polystyrene calibration). IR (KBr), $v=3050,2936,2860$, $1714,1672,1524,1502,1478,1386,1358,1204,1142,1096,1012,960$, $814,788,700 \mathrm{~cm}^{-1}$. ${ }^{1} \mathrm{H}$ NMR $\left(300 \mathrm{MHz} \mathrm{CDCl}_{3}, \mathrm{TMS}, \delta\right): 7.89,7.41,7.34$, 7.26, 7.09, 7.03, 6.09, 5.81. ${ }^{13} \mathrm{C}$ NMR $\left(75 \mathrm{MHz} \mathrm{CDCl}_{3}, \mathrm{TMS}, \delta\right): 168.1$, $164.5,163.2,151.9,149.0,143.5,141.0,140.3,135.9,135.0,134.1,133.7$, 132.2, 131.3, 128.3, 127.8, 127.7, 120.7, 114.8, 112.8 .

Characterization Data for P1/3: White powder; yield 97.2\%. $M_{\mathrm{w}} 29000$, $M_{\mathrm{w}} / M_{\mathrm{n}} 1.7$ (GPC, polystyrene calibration). IR (thin film), $v=3061,2965$, 2926, 2866, 1714, 1574, 1505, 1475, 1392, 1359, 1205, 1169, 1144, 1100, $1080,1012,961,818,734 \mathrm{~cm}^{-1}$. ' $\mathrm{H}$ NMR $\left(300 \mathrm{MHz} \mathrm{CDCl}_{3}, \mathrm{TMS}, \delta\right): 8.02$, $7.96,7.91,7.45,7.43,7.40,7.32,7.26,7.23,7.08,7.05,6.99,6.96,6.16$, $6.12,5.83,5.81,1.78 .{ }^{13} \mathrm{C} \mathrm{NMR}\left(75 \mathrm{MHz} \mathrm{CDCl}_{3}, \mathrm{TMS}, \delta\right): 164.8,151.6$, $148.5,148.4,146.9,135.9,135.2,133.7,132.5,132.1,132.0,131.8,131.8$, $131.3,128.4,120.9,114.9,122.8,42.5,31.0$.

Characterization Data for P1/4: White powder; yield 87.2\%. $M_{\mathrm{w}} 7500$; $M_{\mathrm{w}} / M_{\mathrm{n}} 2.1$ (GPC, polystyrene calibration). IR (thin film), $v=3062,2092$, $1724,1568,1474,1388,1356,1324,1296,1210,1134,1102,1012,958$, $818,734 \mathrm{~cm}^{-1}$. ${ }^{1} \mathrm{H}$ NMR $\left(300 \mathrm{MHz} \mathrm{CDCl}_{3}, \mathrm{TMS}, \delta\right): 8.00,7.98,7.95,7.77$, $7.74,7.52,7.49,7.44,7.41,7.38,7.35,7.32,7.26,6.25,7.23,7.08,7.05$, $6.90,6.87,6.14,6.11,5.81,5.77 .{ }^{13} \mathrm{C} N M R\left(75 \mathrm{MHz} \mathrm{CDCl}_{3}, \mathrm{TMS}, \delta\right): 167.5$, $163.1,162.5,161.2,154.4,154.2,153.7,153.5,150.6,138.4,136.1,135.1$, $134.9,134.6,134.1,133.8,133.5,132.6,131.8,131.3,130.4,129.9,129.3$, $128.9,128.3,122.5,122.3,116.2,113.6,111.8$.

Characterization Data for P1/5: White powder; yield $98.2 \%$. IR (thin film), $v=3058,2924,2856$, 1708, 1570, 1486, 1386, 1358, 1202, 1136, $1098,1012,960,816,788 \mathrm{~cm}^{-1}$. (No GPC and NMR data due to insolubility of the polymer.)

Model Reaction: Phenyl 3-(phenylthio)acrylate (8) was designed and prepared as a model compound by alkyne hydrothiolation of thiophenol (6) and phenyl propiolate (7; Scheme 2). The experimental procedures were similar to those described above for the synthesis of $\mathrm{P} 1 / 2$. A white solid of 8 was obtained $94.0 \%$ yield. ${ }^{7} \mathrm{H}$ NMR $\left(300 \mathrm{MHz}, \mathrm{CDCl}_{3}, \mathrm{TMS}, \delta\right): 8.01,7.48$, $7.45,7.34,7.179,7.15,7.08,6.09,5.82 ;{ }^{13} \mathrm{C} \mathrm{NMR}\left(75 \mathrm{MHz} \mathrm{CDCl}_{3}, \mathrm{TMS}, \delta\right)$ : $164.5,163.4,152.6,150.4,135.6,133.0,131.0,129.7,129.2,128.3,125.6$, $121.5,114.2,112.1$.

Cobalt Complexation: In a $30 \mathrm{~mL}$ test tube was dissolved $58 \mathrm{mg}$ of $\mathrm{P} 1 / 3$ in $10 \mathrm{~mL}$ of THF under nitrogen. Into the mixture, a THF solution of $\mathrm{Co}_{2}(\mathrm{CO})_{8}(5 \mathrm{~mL}, 17 \mathrm{mg})$ was added. The solution was stirred at room temperature for $1 \mathrm{~h}$, after which the solvent was evaporated to about half of its original volume under reduced pressure. The solution was then added dropwise into a large volume of hexane $(\sim 200 \mathrm{~mL})$ under stirring. The precipitate was washed with hexane several times to remove the unreacted octacarbonyldicobalt and then dried under vacuum to a constant weight. A pale purple powder of $\mathrm{P} \mathbf{1} / \mathbf{2}(\mathrm{Co})$ was obtained.

Photoresist Patterning: Photo-crosslinking reactions of the polymer films were conducted in air at room temperature using a $365 \mathrm{~nm}$ light obtained from a Spectroline ENF-280C/F UV lamp as light source at a distance of $1 \mathrm{~cm}$. The incident light intensity was $\sim 18.5 \mathrm{~mW} \mathrm{~cm}{ }^{-2}$. The film was prepared by spin-coating the polymer solution $(10 \% \mathrm{w} / \mathrm{w}$ in 1,2 dichloroethane) at $2000 \mathrm{rpm}$ for $1 \mathrm{~min}$ on a silicon wafer. The polymer film was dried in a vacuum oven at room temperature overnight. The photoresist patterns were generated by irradiating the polymer films for 3 min through a copper photomask. The films were developed in 1,2dichloroethane for $40 \mathrm{~s}$ and dried at room temperature overnight under reduced pressure. The three-dimensional patterns were images on an optical microscope (Olympus B202) using a normal light and a fluorescent optical microscope (Olympus BX41) with a 330-385 wideband UV excitation.

\section{Acknowledgements}

This work was partially supported by the Research Grants Council of Hong Kong (603509, 601608 and 602707), the National Natural Science Foundation of China (20634020 and 20974028), and the University Grants Committee of Hong Kong (AoE/P-03/08). B.Z.T. acknowledges the support from the Cao Guangbiao Foundation of Zhejiang University. Supporting Information is available online from Wiley InterScience or from the author.

Received: October 15, 2009

Revised: January 17, 2010 Published online: March 15, 2010

[1] a) H. Shirakara, Angew. Chem. Int. Ed. 2001, 40, 2575. b) A. G. MacDiarmid, Angew. Chem. Int. Ed. 2001, 40, 2581. c) A. J. Heeger, Angew. Chem. Int. Ed. 2001, 40, 2591.

[2] For reviews, see: a) S. K. Choi, Y. S. Gal, S. H. Jin, H. K. Kim, Chem. Rev. 2000, 100, 1645. b) H. F. Bunz, Acc. Chem. Res. 2001, 34, 998. c) M. B. Nielsen, F. Diederich, Chem. Rev. 2005, 105, 1837. d) T. Masuda, J. Polym. Sci, Part A: Polym. Chem. 2007, 45, 165. e) J. Wu, W. Pisula, K. Mullen, Chem. Rev. 2007, 107, 718. f) S. W. Thomas, G. D. Joly, T. Swager, Chem. Rev. 2007, 107, 1339. g) Y. Morisaki, Y. Chujo, Prog. Polym. Sci. 2008, 33, 346. h) M. Häußler, A. Qin, B. Z. Tang, Adv. Polym. Sci. 2007, 209, 1. i) J. W. Y. Lam, B. Z. Tang, J. Polym. Sci, Part A: Polym. Chem. 2003, 41, 2607.

[3] W. E. Truce, J. A. Simms, J. Am. Chem. Soc. 1956, 12, 2756.

[4] a) K. Griesbaum, Angew. Chem. Int. Ed. 1970, 9, 273. b) I. C. Paul, in The Chemistry of the Thiol Group, Vol. 2 (Ed: S. Patai), Wiley, London 1974. c) V. P. Ananikov, D. A. Malyshev, I. P. Beletskaya, G. G. Aleksandrov, I. L. Eremenko, Adv. Synth. Catal. 2005, 347, 1993.

[5] a) Y. Ichinose, K. Wakamatsu, K. Nozaki, J. L. Birbaum, K. Oshima, K. Utimata, Chem. Lett. 1987, 1671. b) J. W. MaDonald, J. L. Corbin, W. E. Newton, Inorg. Chem. 1976, 15, 9. c) H. Kuniyasu, A. Ogawa, K. I. Sato, I. Ryu, N. Kambe, N. Sonoda, J. Am. Chem. Soc. 1992, 114, 5902. d) J. E. Bäckvall, A. Ericcson, J. Org. Chem. 1994, 59, 5850. e) L. B. Han, C. Zhang, H. Yazawa, S. Shimada, J. Am. Chem. Soc. 2004, 126, 5080. f) A. Ogawa, T. Ikeda, K. Kimura, T. Hirao, J. Am. Chem. Soc. 1999, 121, 5108. g) S. Burling, L. D. Field, B. A. Messerle, K. Q. Vuong, P. Turner, J. Chem. Soc, Dalton Trans. 2003, 4181. h) C. Munro-Leighton, S. A. Delp, N. M. Alsop, E. D. Blue, T. B. Gunnoe, Chem. Commun. 2008, 111. i) C. Cao, L. R. Fraser, J. A. Love, J. Am. Chem. Soc. 2005, 127, 17614. j) A. Kondoh, H. Yorimitsu, K. Oshima, Org. Lett. 2008, 9, 1383. k) D. A. Malyshev, N. M. Scott, N. Marion, E. D. Stevens, V. P. Ananikov, I. P. Beleskaya, S. P. Nolan, Organometallics 2006, 25, 5562. I) A. Sabarre, J. Love, Org. Lett. 2008, 10, 3941. m) C. Cao, T. Wang, B. O. Patrick, J. A. Love, Organometallics 2006, 25, 1321.

[6] A. Kondoh, K. Takami, H. Yorimitsu, K. Oshima, J. Org. Chem. 2005, 70, 6468. 
[7] a) T. Nakamura, N. Tsutsumi, J. Appl. Phys. 2005, 97, 054505 b) Y. G. Yu, G. Almuneau, T. H. Kim, B. W. Lee, Jpn. J. Appl. Phys. 2006, 45, 2546. c) M. Suwa, H. Niwa, M. Tomikawa, J. Photopolym. Sci. Technol. 2006, 19, 275. d) J. Nakai, T. Aoki, US Patent 7087945, 2006. e) J. L. Regolini, D. Benoit, P. Morin, Microelectron Reliab. 2007, 47, 739.

[8] a) P. Mongrain, P. D. Harvey, Macromol. Rapid Commun. 2008, 29, 1752. b) C. M. Elliott, J. R. Dunkle, S. C. Paulson, Langmuir 2005, 21, 8605 c) S. Huang, A. W. H. Mau, J. Phys. Chem. B 2003, 107, 8285.

[9] a) J. Shi, B. Tong, Z. Li, J. Shen, W. Zhao, H. Fu, J. Zhi, Y. Dong, M. Häußler, J. W. Y. Lam, B. Z. Tang, Macromolecules 2007, 40, 8195. b) J. Li, Z. Zhang, Z. Zheng, L. Guo, G.Xu, Z.Xie,J. Appl. Polym. Sci. 2007, 105, 1786.c) L. Friebe, K. Liu, B. Obermeier, S. Petrov, P. Dube, I. Manners, Chem. Mater. 2007, 19, 2630. d) J. Shi, C. J. W. Jim, F. Mahtab, J. Liu, J. W. Y. Lam, H. H. Y. Sung, I. D. Williams, Y. Dong, B. Z. Tang, Macromolecules 2010, 43, 680.

[10] a) J. W. Y. Lam, B. Z. Tang, Acc. Chem. Res. 2005, 38, 745. b) H. Dong, R. Zheng, J. W. Y. Lam, M. Haussler, A. Qin, B. Z. Tang, Macromolecules 2005, 38, 6382. c) C. K. W. Jim, A. Qin, J. W. Y. Lam, M. Haussler, J. Liu, M. M. F. Yuen, J. K. Kim, K. M. Ng, B. Z. Tang, Macromolecules 2009, 42, 4099. d) J. Liu, J. W. Y. Lam, B. Z. Tang, Chem. Rev. 2009, 109, 5799. e) A. Qin, L. Tang, J. W. Y. Lam, C. K. W. Jim, Y. Yu, H. Zhao, J. Sun, B. Z. Tang, Adv. Funct. Mater. 2009, 19, 1891.

[11] For recent reviews on click polymerizations, see: a) A. Qin, J. W. Y. Lam, B. Z. Tang, Chem. Soc. Rev. 2010, 39, DOI: 10.1039/b909064a. b) B. S. Sumerlin, A. P. Vogt, Macromolecules 2010, 43, 1.

[12] a) K. L. Killops, L. M. Campos, C. J. Hawker, J. Am. Chem. Soc. 2008, 130, 5062. b) J. W. Chan, B. Yu, C. E. Hoyle, A. B. Lowe, Chem. Commun. 2008 4959. c) C. Rim, D. Y. Son, Tetrahedron Lett. 2009, 50, 4161.

[13] a) O. Coulembier, L. Mespouille, J. L. Hedrick, R. M. Waymouth, P. Dubois, Macromolecules 2006, 39, 4001. b) B. C. Wilson, C. W. Jones, Macromolecules 2004, 37, 9709.

[14] a) R. S. Edmundson, in Dictionary of Organometallic Compounds (Ed: J. Buckingham), Chapman and Hall, London 1984. b) H. B. Kagan, in Organometallics, 2nd ed. (Eds: C. Elschenbroich, A. Salzer), Wiley-VCH, Weinheim, Germany 1992.

[15] S.-J. Bao, Y. Li, C. M. Li, Q. Bao, Q. Lu, J. Guo, Cryst. Growth Design 2008, 8 , 3745.

[16] a) E. Otsuka, K. Kurumada, A. Suzuki, S. Matsuzawa, K. Takeuchi, J. Sol. -Gel Sci. Technol. 2008, 46, 71. b) J. B. Chu, S. M. Huang, H. B. Zhu, X. B. Xu, Z. Sun, Y. W. Chen, F. Q. Huang, J. Non-Cryst. Solids 2008, 354, 5480.

[17] a) R. Okutsu, Y. Suzuki, S. Ando, M. Ueda, Macromolecules 2008, 41, 6165. b) J.-G. Liu, M. Ueda, J. Mater. Chem. 2009, 19, 8907. c) T. Fushimi, H. R. Allcock, Dalt. Trans. 2009, 14, 2477.
[18] a) K. H. Chen, C. C. Hsu, D. C. Su, Appl. Phys. B 2003, 77, 839. b) T. Kamata, T. Kodzasa, T. Tano, H. Ushijima, MCLC SQT, Sect. B: Nonlinear Opt. 2000 24, 51. c) C. Lü, C. Guan, Y. Liu, Y. Cheng, B. Yang, Chem. Mater. 2005, 17 2448. d) Y. Rao, B. Antalek, J. Minter, T. Mourey, T. Blanton, G. Slater, L. Slater, J. Fornalik, Langmuir 2009, 25, 12713. e) W. Pacuski, C. Kruse, S. Figge, D. Hommel, Appl. Phys. Lett. 2009, 94, 191 108/1. f) C. Lue, B. Yang, J. Mater. Chem. 2009, 19, 2884. g) J. K. Yaho, H. L. Huang, J. Y. Ma, Y. X. Jim, Y. A. Zhao, J. D. Shao, H. B. He, K. Yi, Z. X. Fan, F. Zhang, Z. Y. Wu, Surf. Eng. 2009, 25, 257. h) Y. Imai, A. Terahara, Y. Hakuta, K. Matsui, H. Hayashi, N. Ueno, Eur. Polym. J. 2009, 45, 630. i) L. Bremer R. Tuinier, S. Jahromi, Langmuir 2009, 25, 2390. j) L. Liang, Y. Xu, D. Wu Y. Sun, Mater. Chem. Phys. 2009, 114, 252. k) H.-W. Su, W.-C. Chen, Macromol. Chem. Phys. 2008, 209, 1778. I) S. De, G. De, J. Phys. Chem. C 2008, 112, 10378. m) C. Paquet, P. W. Cyr, E. Kumacheva, I. Manners, Chem. Commun. 2004, 234

[19] a) C. J. Yang, S. A. Jenekhe, Chem. Mater. 1995, 7, 1276. b) C. J. Yang, S. A. Jenekhe, Chem. Mater. 1994, 6, 196.

[20] a) J. C. Seferis, in Polymer Handbook, 3rd ed. (Eds: J. Brandrup, E. H. Immergut), Wiley, New York 1989, pp. VI/451-461. b) N. J. Mills, in Concise Encyclopedia of Polymer Science and Engineering (Ed.: ). I. Kroschwitz), Wiley, New York 1990, pp. 683-687.

[21] a) E. S. Devrim, M. U. Kahveci, M. A. Tasdelen, K. Ito, Y. Yagci, Desig. Monom. Polym. 2009, 12, 265. b) Q. Wu, B. Qu, M. Sun, J. Appl. Polym. Sci. 2009, 114, 562. c) P. A. Di, P. Compston, J. Mater. Sci. 2009, 44, 4188. d) M. Black, J. W. Rawlins, Eur. Polym. J. 2009, 45, 1433. d) S. Miyanishi, K. Tajima, K. Hashimoto, Macromolecules 2009, 42, 1610. e) D. E. Nikles, M. S. Farahat, J. Appl. Polym. Sci. 2009, 111, 3058. f) S. Bitsch, O. Nickslass, L. P. Cristiano, N. W. G. Toung, P. J. Skov, P. R. Ogilby, Langmuir 2009, 25 1148. g) T. F. Scott, W. D. Cook, J. S. Forsythe, Eur. Polym. J. 2008, 44, 3200. h) J. Jang, S. H. Kim, S. Nam, D. S. Chung, C. Yang, W. M. Wun, C. E. Park, J. B. Koo, Appl. Phys. Lett. 2008, 92, 14 3306/1.

[22] For recent reviews, see: a) M. Wang, G. Zhang, D. Zhang, D. Zhu, B. Z Tang, J. Mater. Chem. 2010, 20, DOI: 10.1039/b921610c. b) Y. Hong, J. W. Y. Lam, B. Z. Tang, Chem. Commun. 2009, 4332.

[23] a) Z. Zhao, Z. Wang, P. Lu, C. Y. K. Chan, D. Liu, J. W. Y. Lam, H. H. Y. Sung, I. D. Williams, Y. Ma, B. Z. Tang, Angew. Chem. Int. Ed. 2009, 48, 7608 b) H. Tong, Y. Hong, Y. Dong, M. Hausssler, Z. Li, J. W. Y. Lam, Y. Dong, H. H. Y. Sung, I. D. Williams, B. Z. Tang, J. Phys. Chem. B 2007, 111, 11 817. c) J. Luo, Z. Xie, J. W. Y. Lam, L. Cheng, H. Chen, C. Qiu, H. S Kwok, X. Zhan, Y. Liu, D. Zhu, B. Z. Tang, Chem. Commun. 2001, 1740 